\title{
FRONTIER: DISCIPLINE-BASED EDUCATION RESEARCH TO ADVANCE AUTHENTIC LEARNING IN AGRICULTURAL AND BIOLOGICAL ENGINEERING
}

\author{
Heidi A. Diefes-Dux ${ }^{1, *}$ \\ ${ }^{1}$ Department of Biological Systems Engineering, University of Nebraska-Lincoln, Lincoln, Nebraska, USA. \\ * Correspondence: heidi.diefes-dux@unl.edu.
}

\begin{abstract}
HighLIGHTS
- Discipline-based education research can provide unique insights for agricultural and biological engineering.

- Authentic learning has the potential to transform teaching practices and student learning.

- Work in the five areas of engineering education research provides a foundation for discipline-specific inquiry.

- An agricultural and biological engineering education research agenda is advised.
\end{abstract}

Keywords. Authentic learning, Discipline-based education research.

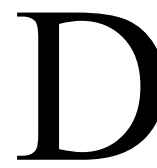
iscipline-based education research (DBER) is research activity aimed at investigating "learning and teaching in a discipline from a perspective that reflects the discipline's priorities, worldview, knowledge, and practices" (NRC, 2012, p. 1) for the purpose of producing research-based evidence to improve education in that discipline. DBER arose out of concerns about the quality of post-secondary science education (NRC, 2012). Physics, chemistry, engineering, biology, geosciences, and astronomy education each have unique DBER histories in the U.S. that date back to the late 1800 s or early 1900s when colleges and university systems were expanding and formalizing. The DBER fields accelerated in the 1950s and 1960s as a result of the Space Race and in subsequent periods of concern about national competitiveness. For engineering education specifically, Mann (1918) argued for the recognition of engineering education research as a viable research enterprise for engineering faculty in the Mann report, the first major study of the state of engineering education. In 1955, the "encouragement of experiments in all areas of engineering education" was a top recommendation in the Grinter Report (1994). Each DBER field, including those that have emerged since the original six, including mathematics (Inglis and Foster, 2018), has been on a path to meet the criteria of a full-fledged field of scientific inquiry, as described by Froyd and Lohmann (2014). This means that each field has, or is in the process of acquiring, structure

\footnotetext{
cC)(1) $\ominus$ The authors have paid for open access for this article. This c. ${ }_{\mathrm{BY}} \mathrm{NC}$ ND work is licensed under a Creative Commons AttributionNonCommercial-NoDerivatives 4.0 International License https://creative commons.org/licenses/by-nc-nd/4.0/

Submitted for review on 1 December 2020 as manuscript number EOPD 14422; approved for publication as an Invited Frontier Article by the Education, Outreach, \& Professional Development Community of ASABE on 11 March 2021.
}

(e.g., national and international societies, academic recognition, and multiple modes of dissemination including archival research journals), distinct research (e.g., knowledge bases, theories, and lines on inquiry), and outcomes (e.g., implications for practice).

DBER takes the perspective that teaching and learning in one discipline are fundamentally different from teaching and learning in another discipline. This means that teaching and learning in agricultural and biological engineering are not the same as in other science, agriculture, or engineering disciplines because our history, our ways of thinking, our learning objectives, and our future trajectory are distinctive. However, DBER is not an insular and introspective enterprise residing solely in any one discipline; rather, it is highly interdisciplinary. It requires researchers trained in the science and engineering spaces to employ a wide range of research methods and to collaborate with researchers from a wide variety of social science spaces (e.g., educational psychology and cognitive science). To transform our educational programs, keep pace with changing needs, and project out to future needs, we need to be cognizant of who we are and the futures for which we are preparing our students and look to the broader community invested in improving STEM education for insights.

The purpose of this article is to challenge us to build a robust agricultural and biological engineering DBER community for advancing educational practices and engaging in education research. To spur us on, this article uses specific examples of new frontiers in each of the five areas of engineering education research (Colloquies, 2006) couched in an overarching theme of authentic learning (e.g., Herrington et al., 2006). The five areas of engineering education research are learning systems, diversity and inclusiveness, learning mechanisms, assessment, and epistemologies. Authentic learning refers to learning strategies employed in the classroom that mimic real-world problem-solving in that the 
learning tasks involve something a practitioner would actually do, application of higher-level thinking skills, natural social interactions in a community, and opportunities for students to direct their own learning. This pedagogical model is selected because most education research with the potential to transform engineering education can be linked to closing the gap between school learning and work in the field.

In the following sections, each area of engineering education research is briefly described. Potentially transformative educational practices or trends in the growing knowledge-base that typifies that area are presented and linked to authentic learning. Potential impacts for agricultural and biological engineering conclude the discussion of each research area.

\section{LEARNING SYSTEMS}

An educational system encompasses "curriculum, courses, organizational structure, and pedagogical practices" (Colloquies, 2006, p. 260). Research on engineering learning systems attends to three components and their interactions: "instructional culture, institutional infrastructure, and the epistemologies of engineering educators" (Colloquies, 2006, p. 260). Instructional culture refers to the shared vision of what effective teaching looks like, expectations for effective teaching, and commitment to improvement. Institutional infrastructure refers to the basic physical and organizational structures and facilities needed to deliver the vision for teaching and learning. The epistemology of engineering educators entails educators' beliefs about how to teach, how students learn, how educators should enact their role as instructors, how educators should interact with each other in matters of the teaching enterprise, and how educator communities should grow and function.

Beliefs about when, where, and how teaching and learning can and does happen are changing. We have experienced this change through a number of pedagogies that have moved learning outside the traditional physical classroom. For instance, service learning has provided practical engineering experiences with real community stakeholders (e.g., Lima and Oakes, 2006). Further, a wide variety of online delivery strategies, from massive open online courses (or MOOCs) (e.g., Iqbal et al., 2014) to blended learning to full degree programs, have made learning anytime and anywhere increasingly the norm. Learning anytime and anywhere has become increasingly realized with the adoption of the hyflex course model (e.g., Liu and Rodriguez, 2019) during the COVID-19 pandemic.

Beliefs about who owns and can create knowledge are also changing. The push for active learning has instilled in us a new view of faculty as facilitators of learning, rather than all-knowing conveyors of knowledge, and students as owners of their own learning rather than vessels waiting to be filled (Weimer, 2002). But where is this shift in beliefs in time, place, and roles taking us? Will shifting beliefs ultimately lead to the complete erosion of programs comprised of sequences of three-credit-hour courses that use a homework and exam structure for learning and assessment, respectively?
Let us look at an extreme example of letting go of that paradigm and consider practice-based education, a pedagogy conceived as a means to address the need to prepare students for actual problem complexity within the constraints of traditional education systems (Mann et al., 2020). This pedagogy is problem-based learning augmented by solving real client problems in teams in an authentic engineering work environment in a curriculum nearly devoid of traditional classroom-based coursework.

A model of practice-based education was envisioned by Swinburne University of Technology in Melbourne, Australia. Swinburne's Bachelor of Engineering Practice was conceived as a four-year professional practice-based immersion honors program. In this program, students complete an engineering degree while acquiring four years of work experience. There are no courses in the traditional sense, such as math, chemistry, physics, thermodynamics, and so on. Rather, the capabilities to be developed fall into five domains: work (teamwork, communication, project management, business acumen, and professionalism), process (research, design, make, and operate), self (being a professional engineer, personal development, and local and global citizenship), thinking, and disciplinary (engineering fundamentals and specialization). Students develop these capabilities as "associates" for the Swinburne Engineering Practice Academy, an organization within the university that "operates as an engineering practice, delivering solutions to industry and community clients" (Mann et al., 2020, p. 8).

In a nutshell, students spend their days, starting in their first year, as professionals in a studio-based learning environment, working side-by-side with practicing engineers, delivering on team-based client-driven projects, and acquiring new knowledge to support their work. The Swinburne curriculum entails engineering practice with credentialing, mentoring and networking with industry partners, and reflective practice. The experience comes with all the professional accoutrements one would expect for a practicing engineer, including commitment to company values, serving on committees, managing deadlines, being on time, and attending meetings. Disciplinary knowledge, such as mathematics, is acquired through a flexible online credentialing system that enables just-in-time learning (Cook, 2018). A credential typically requires six hours of effort spent reading, viewing video content, working examples, or attending face-to-face workshops and ultimately providing evidence of an ability to apply what was learned in practice.

The Swinburne model of practice-based education in engineering is complex, and a quick overview does not do it justice. As one might imagine, there is a substantial investment in curriculum development, establishing and maintaining industry partnerships, and supporting and monitoring students through to degree attainment. Sadly, while Swinburne admitted the first cohort in fall 2019, the university put a hold on further enrollments into the program for reasons unknown. However, the intention embedded in this model to empower students while providing clear expectations, pathways to attainment, and meaningful assessment is remarkable for its potential to prepare students for complexity. 


\section{IMPLICATIONS FOR AGRICULTURAL AND BIOLOGICAL ENGINEERING}

Clearly, most traditional engineering colleges or departments do not have a well-established organization of practicing engineers that serves clients to leverage the development of a practice-based education degree program. As such, can the principles of practice-based education be applied at smaller scales, say within a single course or semester? Senior capstone design courses come to mind. However, many senior capstone courses encompass a limited selection of the practice-based education elements, primarily requiring students to work in teams on a design project. Senior capstone is often delivered as a culminating experience, emphasizing demonstration of the knowledge and skills acquired in previous coursework. There are often only modest needs for students to acquire new knowledge, and professional skills development is included to fill curricular gaps (e.g., project management). Immersion in day-to-day operations, balancing personal goals and development with professional responsibilities, and daily interactions with more senior practitioners are far less common.

How could coursework be repackaged to immerse agricultural and biological engineering students in authentic practice within the curriculum before their senior year, while they are in the throes of learning engineering science? Take for example my own work-in-progress attempt at a juniorlevel introduction to process engineering. The course is modeled as a training program for a non-for-profit engineering consulting group that provides conceptual and practical engineering support for small businesses and startups in rural communities. The course is divided into segments that each include a project that drives the learning of traditional course content, which is delivered through online modules paired with more traditional problem-solving, process-focused grading, and student reflection. Each project is framed as building the tools that the students will need for situations they might encounter while working in the field for the consulting group. This course is perhaps closer to a cognitive apprenticeship (e.g., Collins et al., 1991), which focuses on immersing students in workplace-like tasks to design and create tangible artifacts while learning practical skills, making the instructor's and students' thinking visible to each other, and encouraging reflection. While this course does not retain the element of near-apprenticeship that practice basededucation provides by having students work with practicing engineers, it does retain some of the other key elements of practice based-education (e.g., authentic tasks, learning driven by tasks, teamwork, and reflection) and provides perhaps a more manageable move toward adoption of authentic learning in our engineering classrooms.

Many discipline-specific questions worthy of DBER need to be answered if we pursue practice-based education at any scale. What beliefs about teaching and learning would our instructors need to embrace to build and sustain these authentic learning environments? How would our vision for students' learning change? How would we adapt physical spaces, grading policies, class time, and other elements of the institutional infrastructure? These are all questions that we need to answer about ourselves and our instructional environments to reap the benefits of authentic learning for our students.

\section{DIVERSITY AND INCLUSIVENESS}

Diversity refers to the characteristics that make groups of people unique; inclusion refers to behaviors and social norms that ensure people feel welcome. We are all familiar with the persistence of issues of inequity in engineering. For over 40 years, much research and programmatic and curricular effort has gone into trying to change the demographic profile of engineering students and graduates (e.g., May and Chubin, 2003; NASEM, 2014), citing diverse perspectives and social networks as a means to improve creativity, innovation, and productivity (Smith-Doerr et al., 2017) and maintain prosperity in a global economy.

Education research in engineering diversity and inclusion considers "how diverse human talents contribute solutions to the social and global challenges and relevance of the engineering profession" (Colloquies, 2006, p. 261). Among the underrepresented groups (i.e., women, ethnic minorities, disabled) that engineering has traditionally sought to engage is another emerging dimension of diversity that has implications for engineering, i.e., neurodiversity.

Neurodiversity encompasses conditions such as attention deficit hyperactivity disorder (ADHD), autism, and dyslexia. Autism is of particular interest because an increasing number of children are being diagnosed with an autism spectrum disorder (ASD). The Centers for Disease Control (CDC, 2020) estimate that 1 in $54(2.2 \%)$ children in the U.S. have autism. Prevalence rates indicate that over half a million youth with an ASD will enter adulthood in the next ten years (HHS, 2017). The U.S. Department of Labor (USDOL, n.d.) notes that "Americans on the autism spectrum experience substantial challenges to attaining competitive integrated employment opportunities that match their interests, gifts, and talents," with many experiencing barriers to completing post-secondary education.

Individuals with an ASD have a greater aptitude for systemizing (analyzing and constructing systems) relative to empathizing (social and emotional reactions) (Baron-Cohen, 2006, 2009), making their potential talents unique and appealing in engineering. Further, they are more likely to gravitate to STEM-related majors, particularly science and computer science, than the population as a whole (Wei et al., 2013). Individuals with high-functioning autism are prepared to attend college and are increasingly doing so in an era of advocacy, early identification, and early and intense intervention.

STEM faculty who have taught students with an ASD note that these students have high attention to detail, can follow complex directions and stay on task, and recognize patterns (Shmulsky et al., 2019), all skills that facilitate some types of engineering work. But challenges exist, particularly when employing authentic learning strategies. Not to stereotype, but attention to detail can lead to fixation for some individuals, and the affinity for following directions can lead to rigidness and inflexibility, as well as a lack of critical thinking and creativity. Further, students with an ASD can express frustration in ways that can result in social problems, and differences in social interaction at the extremes can lead to over- and under-participation in teamwork. 


\section{IMPLICATIONS FOR AGRICULTURAL}

\section{AND BIOLOGICAL ENGINEERING}

The research on autism at the university level is only beginning to emerge and often focuses on students' transition to the university. In the meantime, there is likely to be a greater number of students with an ASD enrolling in engineering, and an increase in the use of authentic learning pedagogies may be especially challenging for these students, particularly because of the teamwork aspect. Fortunately, these students, like all students, will likely have greater potential to thrive in environments designed for inclusivity. There is evidence that the use of inclusive pedagogies, as part of Universal Design for Learning (UDL), not only supports women, ethnic minorities, and students with disabilities but benefits all students (e.g., Orr and Hammig, 2009). The central tenets of UDL call for the intentional use of multiple means of presentation (e.g., video, images, text), teaching strategies that provide supports for learning (e.g., study aids, help with writing, and instruction on learning strategies such as time management, proofreading, etc.), multiple assessment strategies (i.e., going beyond traditional exams as the sole means of assessment), and multiple means to build student-faculty relationships (e.g., the instructor showing interest in the subject, conveying why a topic is important, and being empathetic) (Orr and Hammig, 2009).

When considering these potential inclusive strategies for facilitating the success of neurodiverse students, DBER within agricultural and biological engineering might ask: What does the pairing of authentic learning and inclusive pedagogies look like in our discipline? What supports are needed to enable faculty to successfully pair and engage all students in authentic learning and inclusive pedagogies? In what ways do these strategies facilitate student-faculty and student-student interactions when neurodiverse students pursue degrees in our discipline?

As systems-oriented thinking becomes increasingly important to our discipline, students with an ASD could be a good fit for our discipline, given their potential talents in this regard. If we look at neurodiversity overall as a strength, in what ways might neurodiverse students find success in our discipline and help us grow as a diverse and inclusive discipline?

\section{LEARNING MECHANISMS}

The engineering learning mechanisms research area entails investigations into how learners develop knowledge and competencies in context (Colloquies, 2006). Research in this area looks at: (1) how knowledge in a specific domain is acquired, interpreted, and integrated to complete tasks; (2) the steps needed to acquire domain knowledge (learning progressions); and (3) how these steps vary across diverse learners. Anything that engineering students are taught or learn that prepares them for the engineering profession can be investigated along these three lines, from fundamental concepts (e.g., the laws of thermodynamics) to engineering skills (e.g., design) to professional skills (e.g., teamwork and ethics). Because the use of learning strategies is a professional skill that can be taught and learned, research along the three lines of inquiry is possible.
Learning strategies are the approaches taken to learn new things on one's own for learning's sake alone, but more typically, in practice, to make decisions or solve problems. When the phrase "life-long learning" first appeared in the ABET EC2000 student outcomes, the phrase was often operationalized as information literacy, i.e., an ability to find, evaluate, organize, use, and communicate information. Now with ABET 2019, engineering degree programs are charged with preparing their graduates to demonstrate an ability to acquire and apply new knowledge as needed, using appropriate learning strategies. To this end, a learning strategy that is emerging in engineering education is reflection. The goal of developing students' skills with reflection is to develop reflective practitioners, those who can make deep meaning of their experiences for the purpose of improvement.

Reflection is the act of examining the features of an experience through a particular lens, with the goal of assigning meanings that can lead to actions (Turns et al., 2014). In an educational setting, the outcome of reflection is typically related to improving learning. Reflection has long been a part of teacher education, but the benefit of engaging engineering students in reflection has been slow to emerge. According to the Consortium to Promote Reflection in Engineering Education, "Reflection and the promotion of reflective techniques are becoming more important in engineering education because of the expanding need for diverse, adaptive, broad-thinking, and nimble engineering experts who can respond to the ever-increasing challenges that society faces" (CPREE, 2020). Backed by the belief that reflection has value for engineers' learning and work, reflection is being used in a wide variety of ways in engineering curricula. While some uses of reflection are not surprising, such as the development of ethical reasoning (Kisselburgh et al., 2016) and enhancing leadership competencies (Hendricks et al., 2018), other uses of reflection are emerging in a less likely place in the engineering curriculum: in foundational engineering science courses. For instance, reflection has been used to adjust students' commonly held misconceptions about heat and mass transfer (Chenette and Ribera, 2016) and help improve computer science students' detection of faults in software (Goswami and Walia, 2016).

Deep meaning-making does not come easily for most people, and most do not inherently understand the value. Approximately $20 \%$ to $30 \%$ of undergraduate engineering students identify reflection as no more than a means of looking back (Carberry et al., 2018; Dickerson et al., 2020), failing to recognize its utility for gaining new insight and directing future choices. Therefore, numerous reflection experiences are necessary to understand the value of reflection to one's learning and practices, consciously make the time for it, recognize when one's thinking is shallow, and employ effective self-prompting to go deeper. This means that students need early and continuous opportunities to engage in reflection. A first-year reflection experience might have students start by reflecting weekly on their learning processes in relation to their achievement with well-articulated course learning objectives (Diefes-Dux and Carberry, 2019), teasing out what is and is not working about actions taken and making plans for improvement. The focus of reflection at higher academic levels may shift to evaluating one's employment of technical 
concepts and process skills during problem-solving or design, or one's interpersonal skills in working on teams or with stakeholders. Further, reflection is an integral part of authentic learning, where it can take on many different forms to enable reflection in action as work is being done and on action as students write about their learning experiences (Schön, 1983). There really are no bounds on the situations in which reflection may be useful to an engineer. The integration of reflection throughout the curriculum can lead to practitioners who are habitually more mindful of what and how something is being learned, studied, investigated, or produced.

\section{IMPLICATIONS FOR AGRICULTURAL AND BIOLOGICAL ENGINEERING}

The inclusion of student reflection has the potential not only to build students' capacity for learning but also to provide a window through which instructors can see the meaning that students are making of their learning. Investigations into students' meaning-making can inform transformations at both the course and curricular level.

Where in our curricula might reflection and the study of students' reflections be most significant for agricultural and biological engineering students and instructors? There are a wide range of possibilities. For instance, reflection could be used as a pedagogical strategy to focus students' attention on regulating their learning of the most difficult concepts in our discipline, their abilities with professional skills (e.g., communication and teamwork), or their engagement in authentic tasks. Alongside the implementation of reflection, DBER studies could aid in identifying the misconceptions that students hold or the common barriers to success with skills development and engagement in work-like activities. The research-to-practice cycle would then lead to informed adjustments to instruction that could be studied for impact.

Reflection could also aid students in developing their identities as agricultural and biological engineers by asking them to first consider their professional interests and trajectories in light of their learning experiences in the classroom or practical experiences in the field and then plan their next steps. From these reflections, DBER could unpack how agricultural and biological engineering identities are evolving in the context of the curriculum. The findings could inform how we help students build a deeper and more coherent understanding of our discipline.

\section{ASSESSMENT}

Assessment is about the methods, instruments, and metrics that can inform engineering education practice and student learning. Because engineering has a +20 -year history of outcomes-based assessment due to ABET EC2000, engineering, as whole, is perhaps savvier about assessment than many other disciplines. The ABET accreditation process has encouraged many engineering faculty, though not all, to learn about rubrics and using data to inform change, although the changes that these data inform are often addressed over a relatively long time horizon.
What does it look like to shorten the feedback loop to say a week or two to affect students' learning as it is occurring? How do we make assessment valuable to both faculty and students in the short term as well as for long-term decision making? A new take on our grading strategies may help, one that sees grading as a high-quality data generating endeavor that enables a wide group of stakeholders to make informed decisions (Diefes-Dux and Ebrahiminejad, 2018) rather than just a means for sorting students.

Grading strategies exist on a continuum from normative grading to adaptive grading (Carberry et al., 2019). Normbased grading is characterized as being summative (coming at the end of an activity) and comparative, wherein each student's performance is directly compared to all others to determine a grade, sometimes through curving. Adaptive grading is characterized by its focus on mastery, immediacy of feedback, and the availability of unlimited attempts to demonstrate mastery. Norm-based grading is designed to select talent (for opportunities like scholarships, admissions to graduate school, etc.) because its focus is on differentiating students. Adaptive grading, with its focus on feedback and practice, is designed to develop talent, enabling every student to be successful. Grading strategies that are more like the latter provide transparency and fairness for all stakeholders by setting clear expectations for learning and assessing student processes and work products according to those, and only those, expectations.

Normative grading practices have been found to have significant downsides (Hicks, 2020). The grades issued when using these practices are not anchored by clear expectations, and an A grade performance in one semester could garner a $\mathrm{C}$ grade in another semester. This means that inferences concerning student learning cannot be drawn from course grades issued using normative grading practices, although such inferences are frequently made by students and instructors as well as administrators, policymakers, and other stakeholders who potentially hold the keys to future opportunities for students and institutions (Johnson, 2008). The consequence is a chilly climate because factors beyond a student's demonstration of learning affect a student's grades. The ensuing sense of unfairness is particularly discouraging to underrepresented students.

Adaptive grading requires alignment between desired learning outcomes, instructional activities, and what is assessed because what mastery looks like must be defined, and authentic ways to demonstrate that mastery need to be devised. When students have access to those definitions and receive feedback that is consistent with those definitions, trust in the assessment process is established. Grades also map back to expectations, allowing inferences to be made about student learning.

Adaptive grading is at the extreme in both its aim to provide authentic assessment of individual students' mastery and the coordination and time necessary to manage unlimited attempts by students to achieve mastery. Course conditions, such as high enrollment or the particular knowledge or skill development focus, may make adoption of adaptive grading difficult. Less extreme grading approaches, such as competency-based, standards-based, or learning objectivebased grading, are based on similar tenets but allow more 
limited feedback and fewer attempts to demonstrate mastery (Carberry et al., 2019), making these strategies more manageable for most instructors. All of these grading strategies are being investigated in a number of engineering courses, including a first-year introduction to engineering (DiefesDux and Ebrahiminejad, 2018), thermodynamics (Post, 2017), and signals and systems (Wierer, 2019). These grading strategies have also been applied to exams (Hylton and Diefes-Dux, 2016) and project-based design (Atwood et al., 2014). Best practices and ways to address barriers to implementation are emerging (Lee et al., 2018).

Some programs are even using these strategies to reshape curricula, particularly where authentic learning strategies are employed. Credentialing, as discussed earlier for the Swinburne model of practice-based education, is a form of competency-based assessment. This strategy was also taken up by Purdue University's Polytechnique Institute to rethink traditional course boundaries, sequencing, and grades (Exter et al., 2015, 2019). While program-level adoption of new grading strategies is happening in fit and starts, it could eventually transform engineering education.

\section{IMPLICATIONS FOR AGRICULTURAL AND BIOLOGICAL ENGINEERING}

Switching from normative to more adaptive grading practices has three practical benefits. First, the switch changes student-faculty interactions over grades because commonly understood expectations enable conversations to become less about the grade itself (the determination of which can be a mystery) and more about the learning that is generating the grade. These are less defensive and more productive conversations for everyone. Second, the products of grading are useful beyond the classroom. For instance, they can be used directly for ABET accreditation because adaptive grading data should map to ABET student outcomes, thus reducing the need for secondary analysis of student work. Third, adaptive grading practices support authentic learning experiences where formative feedback (feedback given along the way) is expected to guide students' learning and work.

Beyond asking when, where, and how we might develop more adaptive-like grading strategies and how students might engage with these strategies lies the really intriguing questions for DBER: how can we design assessment strategies that mimic or enhance the feedback behaviors used in professional practice in our discipline? How authentic can assessment be and still serve the purpose of providing grades? Overall, when considering our assessment strategies, we have to ask ourselves, what are our beliefs about the purpose of grading and grades?

It is acknowledged that more adaptive-like strategies require considerable mental effort to clearly articulate the standards and employ them faithfully during assessment of student work. To expedite the process, it may be advisable for the entire discipline to share this load. Such sharing could help us collectively better define who we are and what our disciplinary expectations really are for student learning, which brings us to the last engineering education research area.

\section{EPISTEMOLOGIES}

The engineering epistemologies research area is very philosophical and seeks to answer these questions: What constitutes engineering thinking and knowledge? How do we come to know engineering? What is engineering learning? And how do we learn to become engineers? (Carberry et al., 2010). "Broadly, the goal of engineering epistemology should be to characterize, clarify, and criticize basic assumptions, foundations, and practices in the production of engineering knowledge" (Kant and Kerr, 2019, p. 688).

Investigations of engineering epistemology have focused on such topics as differentiating engineering from science generally and by discipline, characterizing the personal epistemologies of engineering students, faculty, and practitioners, and describing and measuring the impact of particular instructional strategies and learning experiences on students' epistemic beliefs. Stating that knowledge acquisition in science is for the purpose of establishing theory, whereas engineering is about the pragmatic use of science, i.e., generating knowledge to be useful (Frezza et al., 2013), sounds simple enough, but there are nuances to these generalizations. Those nuances clearly explain how disciplines differ in their view and use of knowledge, which has potential to guide the articulation of learning expectations and the design of curricula, ultimately helping undergraduate students frame and value what engineers do.

Disciplines have unique epistemic frames that "include standardized discipline-specific vocabulary, ways of understanding a problem, and approaches to processes and tasks" (Walker et al., 2019, p. 211). Frames are characterizations of practice that capture the network of professionals' knowledge, skills, values, identity, and decision-making processes. Frames are informally and somewhat unconsciously agreed upon by the community of practitioners. What is tricky is that the epistemic beliefs of students and instructors can be different from each other and from practicing engineers, making it difficult for instructors to design curricula that instill in students an understanding of the nature of engineering practice (generally and in the discipline) and difficult for students to understand the purpose of their educational experiences. Alignment of epistemic beliefs among stakeholders, or lack thereof, can have consequences for recruitment, retention, teaching, and learning.

There is evidence that the epistemic beliefs of engineering students can be naive (Carberry et al., 2010), but they can adopt more practitioner-like frames through more authentic learning experiences. Examples of authentic learning experiences that have been investigated for their impact on students' epistemic beliefs are studio culture for senior design (Walker et al., 2019) and virtual internships (Arastoopour et al., 2016), among others. Further, research has been conducted in a few disciplines to track changes in students' discipline-specific engineering epistemologies across the curriculum and to characterize the epistemologies of students, faculty, and practitioners. Notable studies have occurred in civil engineering (Brown et al., 2013; Montfort et al., 2014) and biomedical engineering (Bell-Huff et al., 2019). 


\section{IMPLICATIONS FOR AGRICULTURAL}

\section{AND BIOLOGICAL ENGINEERING}

The question we might ask ourselves is, what are our epistemic beliefs and how are they different from related disciplines? We have an intuitive sense that what we know and do, and what we train our students to know and do, is different from mechanical engineers or chemical engineers, often pointing to our "biology-ness" and "practical-ness." However, employers are often unaware of the particular knowledge, skills, and abilities that our students possess (London and Moore, 2020).

At a time when other disciplines are co-opting at least our "biology-ness," it is perhaps imperative that DBER methods be employed to formally investigate who we are as agricultural and biological engineers, who we impact through our work, and how we interact with the world through our work. We might pursue questions about how we formulate problems and what contextual factors we consider when formulating problems. We could analyze the nature of the evidence (e.g., information, facts, and data) that we use in our work, and how technology and social imperatives influence what we count as evidence. We could investigate the role of professionalism in our discipline. These investigations would likely result in new modes of thinking and ways of dealing with complex problems that are in our purview. More importantly, such investigations would help us understand ourselves, enabling us to clearly explain ourselves to others. That ability has far-reaching implications for diversifying our community and raising the value of our discipline.

\section{GOING FORWARD}

When looking at just authentic learning and the five areas of engineering education research that inform our understanding of how to design, implement, and assess educational experiences, we should come to the conclusion that there are considerable opportunities for DBER to impact our discipline. To be effective consumers of and contributors to engineering education research, we need a stronger education research foundation within our discipline that reflects the traditions and values of our discipline. This requires going beyond providing space at ASABE and ASEE national conferences to share our classroom and outreach intervention work to establishing an agricultural and biological engineering education research agenda and setting expectations for producing high-quality research that informs and transforms teaching practices in our discipline. Such expectations cannot be met without fundamental education research training for existing faculty, strong collaborations between existing faculty and education researchers, and growth in the number of DBER-trained researchers with backgrounds in agricultural and biological engineering.

\section{REFERENCES}

Arastoopour, G., Shaffer, D. W., Swiecki, Z., Ruis, A. R., \& Chesler, N. C. (2016). Teaching and assessing engineering design thinking with virtual internships and epistemic network analysis. Intl. J. Eng. Educ., 32(3B), 1492-1501. Retrieved from https://www.ijee.ie/contents/c320316B.html

Atwood, S. A., Siniawski, M. T., \& Carberry, A. (2014). Using standards-based grading to effectively assess project-based design courses. Proc. ASEE Annual Conf. Washington, DC: American Society for Engineering Education. https://doi.org/10.18260/1-2--23278

Baron-Cohen, S. (2006). The hyper-systemizing, assortative mating theory of autism. Prog. Neuropsychopharmacol. Biol. Psychiatry, 30(5), 865-872. https://doi.org/10.1016/j.pnpbp.2006.01.010

Baron-Cohen, S. (2009). Autism: The empathizing-systemizing (ES) theory. Ann. New York Acad. Sci., 1156(1), 68-80. https://doi.org/10.1111/j.1749-6632.2009.04467.x

Bell-Huff, C. L., Fernandex, T. M., Morgan, K. L., \& LeDoux, J. M. (2019). WIP: How students externalize epistemologies: Describing how students explain, ground, and consciously construct their definitions of engineering and biomedical engineering. Proc. ASEE Annual Conf. Washington, DC: American Society for Engineering Education. https://doi.org/10.18260/1-2--33563

Brown, S. A., Montfort, D., \& Frye, N. L. (2013). What is engineering knowledge: A longitudinal study of conceptual change and epistemology of engineering students and practitioners. Proc. ASEE Annual Conf. Washington, DC: American Society for Engineering Education. https://doi.org/10.18260/1-2--22750

Carberry, A. R., Atwood, S. A., Siniawski, M. T., \& Diefes-Dux, H. A. (2019). A comparison and classification of grading approaches used in engineering education. Proc. SEFI Annual Conf. (pp. 216-225). Brussels, Belgium: European Society for Engineering Education (SEFI). Retrieved from https://www.sefi.be/wpcontent/uploads/2019/10/SEFI2019_Proceedings.pdf

Carberry, A., Harding, T., Cunningham, P., Csavina, K., Ausman, M., \& Lau, D. (2018). Professional and personal use of reflection by engineering faculty, students, and practitioners. Proc. ASEE Annual Conf. Washington, DC: American Society for Engineering Education. https://doi.org/10.18260/1-2--30896

Carberry, A., Ohland, M., \& Swan, C. (2010). A pilot validation study of the epistemological beliefs assessment for engineering (EBAE): First-year engineering student beliefs. Proc. ASEE Annual Conf. Washington, DC: American Society for Engineering Education. https://doi.org/10.18260/1-2--15693

CDC. (2020). Data and statistics on autism spectrum disorder. Atlanta, GA: Centers for Disease Control. Retrieved from https://www.cdc.gov/ncbddd/autism/data.html

Chenette, H. C., \& Ribera, T. (2016). Prediction and reflection activities in a chemical engineering course: Fundamentals of heat and mass transfer. Proc. ASEE Annual Conf. Washington, DC: American Society for Engineering Education. https://doi.org/10.18260/p.27334

Collins, A., Brown, J. S., \& Holum, A. (1991). Cognitive apprenticeship: Making thinking visible. American Educator, 15(3), 6-11.

Colloquies. (2006). The research agenda for the new discipline of engineering education. J. Eng. Educ., 95(4), 259-261. https://doi.org/10.1002/j.2168-9830.2006.tb00900.x

Cook, E. (2018). Mathematical competencies and credentials in a practice-based engineering degree. Proc. 19th SEFI Mathematics Working Group Seminar on Engineering Education (pp. 147-152). Brussels, Belgium: European Society for Engineering Education (SEFI).

CPREE. (2020). Consortium to Promote Reflection in Engineering Education. Seattle, WA: University of Washington, Center for 
Engineering Learning and Training, Retrieved from cpree.uw.edu

Dickerson, S. J., Clark, R. M., \& Jiang, N. (2020). Assessment of reflective and metacognitive practices for electrical and computer engineering undergraduates. Proc. ASEE Virtual Annual Conf. Content Access. Washington, DC: American Society for Engineering Education. https://doi.org/10.18260/1-2$-34193$

Diefes-Dux, H. A., \& Carberry, A. R. (2019). Cases of student reflection within a course using standards-based grading. Proc. IEEE Frontiers in Education Conf. Piscataway, NJ: IEEE. https://doi.org/10.1109/FIE43999.2019.9028501

Diefes-Dux, H. A., \& Ebrahiminejad, H. (2018). Standards-based grading derived data to monitor grading and student learning. Proc. ASEE Annual Conf. Washington, DC: American Society for Engineering Education. https://doi.org/10.18260/1-2--30981

Exter, M., Ashby, I., \& Caskurlu, S. (2019). Elusive expectations for a novel program design: Contrast between program intentions and student recruitment and retention. J. CompetencyBased Educ., 4(3), e01192. https://doi.org/10.1002/cbe2.1192

Exter, M., Ashby, I., \& Shaurette, M. (2015). Entering the first year of a multidisciplinary, hands-on, competency-based learning experience: Hopes and concerns of students, parents, and faculty. Proc. ASEE Annual Conf. Washington, DC: American Society for Engineering Education. https://doi.org/10.18260/p.24014

Frezza, S., Nordquest, D., \& Moodey, R. (2013). Knowledgegeneration epistemology and the foundations of engineering. Proc. IEEE Frontiers in Education Conf. (pp. 818-824). Piscataway, NJ: IEEE. https://doi.org/10.1109/FIE.2013.6684940

Froyd, J. E., \& Lohmann, J. R. (2014). Chronological and ontological development of engineering education as a field of scientific inquiry. In A. Johri \& B. M. Olds (Eds.), Cambridge handbook of engineering education research (pp. 3-26). New York, NY: Cambridge University Press. https://doi.org/10.1017/CBO9781139013451.003

Goswami, A., \& Walia, G. S. (2016). Teaching software requirements inspections to software engineering students through practical training and reflection. Proc. ASEE Annual Conf. Washington, DC: American Society for Engineering Education. https://doi.org/10.18260/p.26049

Grinter Report. (1994). Report on evaluation of engineering education (reprint of the 1955 report). J. Eng. Educ., 93(1), 7494.

Hendricks, D. G., Yasuhar., K., \& Taylor, A. C. (2018). Enhancing student leadership competencies through reflection. Proc. ASEE Annual Conf. Washington, DC: American Society for Engineering Education. https://doi.org/10.18260/1-2--30428

Herrington, A., Herrington, T., \& Herrington, J. (2006). Authentic learning environments in higher education. Hershey, PA: IGI Global. https://doi.org/10.4018/978-1-59140-594-8

HHS. (2017). Young adults and transitioning youth with autism spectrum disorder. Washington, DC: U.S. Department of Health and Human Services. Retrieved from

https://www.hhs.gov/sites/default/files/2017AutismReport.pdf

Hicks, N. M. (2020). A variability analysis of grading open-ended tasks with rubrics across many graders. $\mathrm{PhD}$ diss. West Lafayette, IN: Purdue University, School of Engineering Education. https://doi.org/10.25394/PGS.12743417.v1

Hylton, J. B., \& Diefes-Dux, H. A. (2016). A standards-based assessment strategy for written exams. Proc. ASEE Annual Conf. Washington, DC: American Society for Engineering Education. https://doi.org/10.18260/p.26444
Inglis, M., \& Foster, C. (2018). Five decades of mathematics education research. J. Res. Math. Educ., 49(4), 462-500. https://doi.org/10.5951/jresematheduc.49.4.0462

Iqbal, S., Zang, X., Zhu, Y., Chen, Y. Y., \& Zhao, J. (2014). On the impact of MOOCs on engineering education. Proc. IEEE Intl. Conf. on MOOC, Innovation and Technology in Education, (pp. 101-104). Piscataway, NJ: IEEE. https://doi.org/10.1109/MITE.2014.7020249

Johnson, M. (2008). Grading in competence-based qualifications: Is it desirable and how might it affect validity? J. Further Higher Educ., 32(2), 175-184. https://doi.org/10.1080/03098770801979183

Kant, V., \& Kerr, E. (2019). Taking stock of engineering epistemology: Multidisciplinary perspectives. Philos. Tech., 32(4), 685-726. https://doi.org/10.1007/s13347-018-0331-5

Kisselburgh, L. G., Hess, J. L., Zoltowski, C. B., Beever, J., \& Brightman, A. O. (2016). Assessing a scaffolded, interactive, and reflective analysis framework for developing ethical reasoning in engineering students. Proc. ASEE Annual Conf. Washington, DC: American Society for Engineering Education. https://doi.org/10.18260/p.26288

Lee, E., Carberry, A. R., Diefes-Dux, H. A., Atwood, S. A., \& Siniawski, M. T. (2018). Faculty perception before, during, and after implementation of standards-based grading. Australasian J. Eng. Educ., 23(2), 53-61. https://doi.org/10.1080/22054952.2018.1544685

Lima, M., \& Oakes, W. C. (2006). Service-learning: Engineering in your community (1st Ed.). Wildwood, MO: Great Lakes Press.

Liu, C.-Y. A., \& Rodriguez, R. C. (2019). Evaluation of the impact of the Hyflex learning model. Intl. J. Innov. Learning, 25(4), 393-411. https://doi.org/10.1504/IJIL.2019.099986

London, C., \& Moore, J. M. (2020). Work in progress: I didn't know you did that: A case study of learning outcomes across multiple engineering disciplines compared to biological and agricultural engineering. Proc. ASEE Annual Conf. Washington, DC: American Society for Engineering Education. https://doi.org/10.18260/1-2--35644

Mann, C. R. (1918). A study of engineering education. Retrieved from https://www.asee.org/member-resources/reports/Mann.pdf

Mann, L., Chang, R., Chandrasekaran, S., Coddington, A., Daniel, S., Cook, E., ... Smith, T. D. (2020). From problem-based learning to practice-based education: A framework for shaping future engineers. European J. Eng. Educ., 46(1), 27-47. https://doi.org/10.1080/03043797.2019.1708867

May, G. S., \& Chubin, D. E. (2003). A retrospective on undergraduate engineering success for underrepresented minority students. J. Eng. Educ., 92(1), 27-39. https://doi.org/10.1002/j.2168-9830.2003.tb00735.x

Montfort, D., Brown, S., \& Shinew, D. (2014). The personal epistemologies of civil engineering faculty. J. Eng. Educ., 103(3), 388-416. https://doi.org/10.1002/jee.20050

NASEM. (2014). Surmounting the barriers: Ethnic diversity in engineering education: Summary of a workshop. Washington, DC: National Academies of Sciences, Engineering, and Medicine. https://doi.org/10.17226/18847

NRC. (2012). Discipline-based education research: Understanding and improving learning in undergraduate science and engineering. Washington, DC: National Research Council. https://doi.org/10.17226/13362

Orr, A. C., \& Hammig, S. B. (2009). Inclusive postsecondary strategies for teaching students with learning disabilities: A review of the literature. Learning Disability Qtly., 32(3), 181196. https://doi.org/10.2307/27740367

Post, S. (2017). Standards-based grading in a thermodynamics course. Intl. J. Eng. Pedagogy, 7(1), 173-181. https://doi.org/10.3991/ijep.v7i1.6472 
Schön, D. A. (1983). The reflective practitioner: How professionals think in action. New York, NY: Basic Books.

Shmulsky, S., Gobbo, K., \& Bower, M. W. (2019). STEM faculty experience teaching students with autism. J. STEM Teacher Educ., 53(2), article 4. https://doi.org/10.30707/JSTE53.2Shmulsky

Smith-Doerr, L., Alegria, S. N., \& Sacco, T. (2017). How diversity matters in the U.S. science and engineering workforce: A critical review considering integration in teams, fields, and organizational contexts. Engaging Sci. Tech. Soc., 3, 139-153. https://doi.org/10.17351/ests2017.142

Turns, J. A., Sattler, B., Yasuhara, K., Borgford-Parnell, J. L., \& Atman, C. J. (2014). Integrating reflection into engineering education. Proc. ASEE Annual Conf. Washington, DC: American Society for Engineering Education. https://doi.org/10.18260/1-2--20668
USDOL. (n.d.). Autism. Washington, DC: U.S. Department of Labor. Retrieved from https://www.dol.gov/agencies/odep/program-areas/autism

Walker, E. B., Boyer, D. M., \& Benson, L. C. (2019). Using studio culture to foster epistemic change in an engineering senior design course. IEEE Trans. Educ., 62(3), 209-215. https://doi.org/10.1109/TE.2019.2898151

Wei, X., Yu, J. W., Shattuck, P., McCracken, M., \& Blackorby, J. (2013). Science, technology, engineering, and mathematics (STEM) participation among college students with an autism spectrum disorder. J. Autism Devel. Disorders, 43(7), 15391546. https://doi.org/10.1007/s10803-012-1700-z

Weimer, M. (2002). Learner-centered teaching: Five key changes to practice. San Francisco, CA: Jossey-Bass.

Wierer, J. (2019). Standards-based grading for signals and systems. Proc. ASEE Annual Conf. Washington, DC: American Society for Engineering Education. https://doi.org/10.18260/1-2--33282 